\title{
Is it better to treat chronic hepatitis $B$ as early as possible?-Con
}

\author{
ANNA SF LOK \\ University of Michigan, Ann Arbor, MI, USA
}

\begin{abstract}
Ideally, treatment of chronic hepatitis B in its early stage prior to irreversible liver damage should be most effective in preventing adverse clinical outcome. However, currently available treatments have low efficacy in achieving sustained response among patients in the early phase of chronic hepatitis $\mathrm{B}$ infection when the immune response to hepatitis B virus is weak. This review will provide evidence why a 'wait and monitor' approach is appropriate for chronic hepatitis B patients who are in the immune tolerant phase.

(C) 2004 Blackwell Publishing Asia Pty Ltd
\end{abstract}

Key words: adefovir dipivoxil, hepatitis B e antigen, immune tolerance, interferon, lamivudine.

\section{INTRODUCTION}

Remarkable progress has been made in the treatment of chronic hepatitis B in the past decade. Treatment options have expanded from a single approved treatment that has to be administered parenterally, has many unpleasant side-effects, is expensive, and has limited efficacy and applicability to three approved treatments including two orally administered antiviral compounds which have very few side-effects. Nevertheless, current treatments are far from satisfactory. Sustained offtreatment response is achieved in a very small percent of patients. Maintenance of on-treatment response requires long-term therapy with increasing costs, and risks of drug-resistance and adverse effects. Thus, decision to initiate treatment must carefully balance longterm benefits against long-term costs and risks, as well as patient preference, age, comorbid conditions and severity of liver disease. The natural history of chronic HBV infection can be depicted as consisting of four phases: immune tolerant phase, immune clearance phase (HBeAg positive chronic hepatitis), inactive carrier state, and reactivation ( $\mathrm{HBeAg}$ negative chronic hepatitis). Treatment guidelines recommend that patients with HBeAg positive chronic hepatitis and those with HBeAg negative chronic hepatitis be treated because antiviral therapy can decrease hepatic necroinflammation and risk of progression of liver disease. ${ }^{1-4}$ Treatment is not recommended for inactive carriers who have low or undetectable serum HBV DNA $\left(<10^{3}\right.$ copies $/ \mathrm{mL}$ ) and normal alanine aminotransferase (ALT) levels. Current treatment will not bring about further improvement and is unlikely to eradicate HBV, clear hepatitis B surface antigen (HBsAg) or prevent future reactivation. These carriers should be monitored and treatment instituted if they should progress to HBeAg negative chronic hepatitis. Much of the controversy regarding hepatitis B treatment is focused on patients in the first phase-immune tolerant phase.

\section{WHAT IS THE IMMUNE TOLERANT PHASE?}

The 'immune tolerant' phase of chronic HBV infection is characterized by the presence of $\mathrm{HBsAg}, \mathrm{HBeAg}$, high serum HBV DNA levels $\left(10^{7}-10^{10}\right.$ copies $\left./ \mathrm{mL}\right)$, persistently normal ALT levels, and minimal or no hepatic inflammation and fibrosis if a liver biopsy is performed. ${ }^{1}$ The classical patient in the 'immune tolerant' phase is a young ( $<30$ years) Asian patient with perinatally acquired $\mathrm{HBV}$ infection.

Evidence of immune tolerance was provided by studies of peripheral blood mononuclear cells in HBeAgpositive Chinese children with normal ALT levels and cord blood mononuclear cells from neonates of HBsAg and $\mathrm{HBeAg}$-positive carrier mothers showing lack of proliferative response to $\mathrm{HBcAg}$ that was not reversed by depleting CD8+ suppressor T cells. ${ }^{5}$ However, it should be noted that tolerance is not permanent because $\mathrm{HBe} / \mathrm{HBcAg}$-specific $\mathrm{T}$ cell proliferative responses have been demonstrated to increase during acute exacerbations of chronic hepatitis $B$ and in HBeAg-positive Chinese children with elevated ALT. ${ }^{5,6}$ 
Longitudinal follow-up studies also showed that elevated ALT and acute exacerbations of chronic hepatitis $B$ can be observed indicating that 'immune tolerance' is a reversible state. ${ }^{7}$

\section{WHAT ARE THE GOALS OF TREATMENT OF HEPATITIS B?}

The primary goal of treatment of hepatitis B is to prevent adverse clinical outcome: cirrhosis, liver failure and HCC. The end-point of treatment of $\mathrm{HBeAg}$-positive patients is $\mathrm{HBeAg}$ to anti-HBe seroconversion with associated suppression of serum HBV DNA to $<100000$ copies $/ \mathrm{mL}$ and normalization of ALT. ${ }^{8}$ Several long-term follow-up studies have demonstrated that responders have improved clinical outcome. Intuitively, maximum benefit would be derived if treatment can be initiated early and response achieved before there is irreversible liver damage. Thus, hepatitis B patients in the immune tolerant phase are ideal candidates for treatment provided effective treatment is available.

\section{WHAT IS THE EFFICACY OF CURRENTLY APPROVED TREATMENTS?}

Three treatments have been approved for chronic hepatitis B: standard interferon alpha (IFNo), lamivudine (Epivir), and adefovir dipivoxil (Hepsera).

\section{IFN $\alpha$}

Clinical trials showed that compared to untreated controls, a 4-6 month course of IFN $\alpha$ treatment results in $\mathrm{HBeAg}$ clearance in an additional 24\% (95\% CI 8\%$30 \%$ ) patients. ${ }^{9}$ The strongest predictor of response is pretreatment ALT level. ${ }^{10,11}$ This explains why studies in Asian patients that included patients with normal or minimally elevated ALT levels reported very poor response to IFN $\alpha$ therapy (Table 1). ${ }^{12-15}$ Subsequent studies found that Asian patients with elevated ALT had similar response rates as Caucasian patients ${ }^{15,16}$ indicating that host immune response at the time treatment is initiated and not genetic factors led to the low response rates in the early studies of Asian patients. These data showed that IFN $\alpha$ has very limited efficacy in $\mathrm{HBeAg}$ clearance-a surrogate marker for sustained viral suppression, in hepatitis B patients who are in the immune tolerant phase. However, Asian patients who have entered the immune clearance phase ( $\mathrm{HBeAg}$ positive, elevated ALT levels) may benefit from IFN $\alpha$ therapy.

A phase II clinical trial of pegylated IFN $\alpha 2$ a reported that among patients with pretreatment ALT $<2$ times upper limit of normal (ULN), a combined response (HBeAg loss, serum HBV DNA $<500000$ copies/mL and ALT normalization) was achieved in six of 22 patients who received pegylated IFN $\alpha 2 \mathrm{a}$ and in only one of 9 who received standard IFN $\alpha 2$ a suggesting that pegylated IFN may have a role in hepatitis B patients who are in the immune tolerant phase. ${ }^{17}$ However, the number of patients was small and the exact number of patients with normal pretreatment ALT was not specified. Given the costs and the associated side-effects, further studies are needed to determine if pegylated IFN $\alpha$ has any role in hepatitis B patients who are in the immune tolerant phase.

\section{Lamivudine}

Clinical trials showed that a 1-year course of lamivudine results in $\mathrm{HBeAg}$ seroconversion in 16-18\% compared to $4-6 \%$ of those who received placebo. ${ }^{18-20}$ As with IFN $\alpha$, pretreatment ALT is the strongest predictor of response to lamivudine. This is true for adults as well as children (Table 2) 21 $^{1}$ and Caucasians as well as Asians (Table 3). ${ }^{22}$ While increasing rates of $\mathrm{HBeAg}$ serocon-

Table 1 Efficacy of IFN $\alpha$ therapy in controlled trials in HBeAg-positive Chinese patients

\begin{tabular}{|c|c|c|c|c|}
\hline Author [ref] & Treatment & No. of patients & Pretreatment ALT $(\times \mathrm{ULN})$ & No. (\%) patients lost $\mathrm{HBeAg}$ \\
\hline \multirow[t]{2}{*}{$\mathrm{Lai}^{12, \dagger}$} & $\mathrm{IFN} \alpha$ & 12 & 0.3 & 0 \\
\hline & Control & 12 & 0.3 & 0 \\
\hline \multirow[t]{2}{*}{$\mathrm{Lai}^{13, \dagger}$} & IFN $\alpha \pm$ Pred & 60 & 0.3 & $5(8)$ \\
\hline & Control & 30 & 0.3 & 0 \\
\hline \multirow[t]{2}{*}{ Lok $^{14, \dagger}$} & $\mathrm{IFN} \alpha$ & 54 & 1.5 & $9(17)$ \\
\hline & Control & 18 & 1.5 & 0 \\
\hline \multirow[t]{4}{*}{ Lok $^{15, \dagger}$} & IFN $\alpha \pm$ Pred & 40 & 0.5 & $1(2.5)$ \\
\hline & Control & 20 & 0.5 & 0 \\
\hline & $\mathrm{IFN} \alpha \pm$ Pred & 39 & 3.5 & $14(36)$ \\
\hline & Control & 16 & 3.0 & $3(19)$ \\
\hline \multirow[t]{2}{*}{$\operatorname{Liaw}^{16, \dagger}$} & $\mathrm{IFN} \alpha \pm$ Pred & 76 & 6.0 & $27(36)$ \\
\hline & Control & 40 & 6.0 & $10(25)$ \\
\hline
\end{tabular}

${ }^{\dagger}$ Studies in children.

Pred, prednisone/prednisolone priming. 
Table 2 HBeAg seroconversion rates after 1 year of lamivudine treatment in relation to pretreatment ALT level ${ }^{19,21}$

\begin{tabular}{lcccc}
\hline & $\begin{array}{c}\text { Pretreatment } \\
\text { ALT }(\times \mathrm{ULN})\end{array}$ & Adults Lamivudine $N(\%)$ & Placebo $N(\%)$ & $\begin{array}{c}\text { HBeAg Seroconversion } \\
\text { Children Lamivudine } n(\%)\end{array}$ \\
\hline$<1$ & $1 / 53(2)$ & $0 / 25(0)$ & $1 / 8(12)$ & $1 / 7(14)$ \\
$1-2$ & $8 / 114(7)$ & $3 / 59(5)$ & $10 / 86(12)$ & $2 / 30(7)$ \\
$2-5$ & $32 / 164(20)$ & $7 / 82(9)$ & $25 / 81(31)$ & $5 / 41(12)$ \\
$>5$ & $25 / 60(42)$ & $4 / 26(15)$ & $8 / 16(50)$ & $4 / 17(24)$ \\
\hline
\end{tabular}

Table 3 HBeAg loss in relation to pretreatment ALT and ethnic origin after 1 year of lamivudine treatment ${ }^{22}$

\begin{tabular}{lcc}
\hline Pretreatment & HBeAg loss & \\
ALT $(\times$ ULN $)$ & Asians & Caucasians \\
\hline $1-2$ & $9 \%$ & $19 \%$ \\
$2-5$ & $26 \%$ & $30 \%$ \\
$>5$ & $59 \%$ & $54 \%$ \\
\hline
\end{tabular}

version can be achieved by extending the duration of lamivudine treatment, only $25 \%$ patients with normal pretreatment ALT had HBeAg seroconversion after 5 years of lamivudine treatment. ${ }^{23}$ The low response rate in relation to a 5-year rate of lamivudine-resistant mutation of $69 \%{ }^{23}$ cannot justify the use of long-term lamivudine treatment for hepatitis B patients who are in the immune tolerant phase. The importance of pretreatment ALT in spontaneous and antiviral therapy related $\mathrm{HBeAg}$ seroconversion was highlighted in an analysis of 805 adults who were treated with lamivudine, IFN $\alpha$, combination of IFN $\alpha$ and lamivudine, and placebo tablets (Table 4). ${ }^{22}$

\section{Adefovir dipivoxil}

Phase III clinical trial of adefovir dipivoxil reported that $\mathrm{HBeAg}$ seroconversion was observed in $12 \%$ and $6 \%$ of patients after 1 year of adefovir dipivoxil $10 \mathrm{mg}$ and placebo, respectively. ${ }^{24} \mathrm{~A}$ combined analysis of patients in this trial and patients in a parallel trial conducted in patients with $\mathrm{HBeAg}$ negative chronic hepatitis showed that histologic response and HBV DNA suppression was comparable in Asian and Caucasian patients. ${ }^{25}$ However, only $2 \%$ of patients in the trial of HBeAgpositive hepatitis had normal pretreatment ALT levels. ${ }^{24}$ Thus, the efficacy of adefovir dipivoxil in hepatitis B patients in the immune tolerant phase remains to be determined.

\section{WHY IS TREATMENT NOT RECOMMENDED FOR HEPATITIS B PATIENTS IN THE 'IMMUNE TOLERANT' PHASE?}

The primary goal of hepatitis B treatment is to prevent adverse clinical outcome. Accomplishment of this
Table 4 HBeAg seroconversion rates in randomized controlled trials of lamivudine, IFN $\alpha$, and lamivudine + IFN $\alpha$ in relation to pretreatment ALT level ${ }^{22}$

\begin{tabular}{lcccc}
\hline $\begin{array}{l}\text { Pretreatment } \\
\text { ALT } \\
(\times \text { ULN })\end{array}$ & Placebo & Lamivudine & IFN $\alpha$ & $\begin{array}{c}\text { Hamivudine } \\
+ \text { IFN } \alpha\end{array}$ \\
\hline$=1$ & 0 & 2 & $50^{\dagger}$ & 0 \\
$1-2$ & 5 & 7 & 9 & 10 \\
$2-5$ & 9 & 20 & 20 & 24 \\
$>5$ & 15 & 42 & 30 & 45 \\
\hline
\end{tabular}

${ }^{\dagger} 1$ of 2 patients.

goal necessitates that treatment can result in sustained off-treatment virologic response, or maintenance of response through continuous therapy. The latter approach is practical only if the therapy is safe, affordable, and has a negligible risk of adverse effects with long-term use. Such therapy is not yet available. Thus, treatment is not recommended for hepatitis B patients in the 'immune tolerant' phase because the long-term benefits of currently available treatments do not outweigh the long-term costs; and risks of adverse effects and drug resistance. Treatment is recommended when 'immune tolerance' is broken and these patients remain HBeAg positive after ALT levels have been elevated for longer than 6 months. Treatment at this stage is more likely to be effective, and to benefit the patients by shortening the period of active liver damage. In conclusion, hepatitis B patients in the immune tolerant phase are ideal candidates for treatment provided effective treatment is available. Until then, the 'immune tolerant' patient should be monitored so treatment can be initiated promptly when the time is ripe.

\section{REFERENCES}

1 Lok AS, McMahon BJ. Chronic hepatitis B-Practice Guidelines Committee, AASLD. Hepatology 2001; 34: 1225-41.

2 Lok AS, McMahon BJ. Chronic hepatitis B: update of recommendations. Hepatology 2004; 39: 857-61.

3 de Franchis R, Hadengue A, Lau G et al. EASL International Consensus Conference on Hepatitis B. 13-14 September, 2002 Geneva, Switzerland. Consensus statement (long version). F. Hepatol. 2003; 39 (Suppl. 1): S325. 
4 Liaw YF, Leung N, Guan R, Lau GK, Merican I. AsianPacific consensus statement on the management of chronic hepatitis B: an update. F. Gastroenterol. Hepatol. 2003; 18: 239-45.

5 Milich D, Liang TJ. Exploring the biological basis of hepatitis $\mathrm{B}$ e antigen in hepatitis B virus infection. Hepatology 2003; 38: 1075-86.

6 Hsu HY, Chang MH, Hsieh $\mathrm{KH}$ et al. Cellular immune response to $\mathrm{HBcAg}$ in mother-to-infant transmission of hepatitis B virus. Hepatology 1992; 15: 770-6.

7 Tsai SL, Chen PJ, Lai MY et al. Acute exacerbations of chronic type $\mathrm{B}$ hepatitis are accompanied by increased $\mathrm{T}$ cell responses to hepatitis $\mathrm{B}$ core and e antigens. Implications for hepatitis $\mathrm{B}$ e antigen seroconversion. F. Clin. Invest. 1992; 89: 87-96.

8 Lok AS, Heathcote EJ, Hoofnagle JH. Management of hepatitis B: 2000 - summary of a workshop. Gastroenterology 2001; 120: 1828-53.

9 Craxi A, Di Bona D, Camma C. Interferon-alpha for HBeAg-positive chronic hepatitis B. F. Hepatol. 2003; 39: S99-105.

10 Lok AS, Ghany MG, Watson G, Ayola B. Predictive value of aminotransferase and hepatitis B virus DNA levels on response to interferon therapy for chronic hepatitis B. $\mathcal{F}$. Viral Hepat. 1998; 5: 171-8.

11 Perrillo RP, Schiff ER, Davis GL et al. A randomized, controlled trial of interferon alfa- $2 b$ alone and after prednisone withdrawal for the treatment of chronic hepatitis B. The Hepatitis Interventional Therapy Group. [see comments]. N. Engl. F. Med. 1990; 323: 295-301.

12 Lai CL, Lok AS, Lin HJ, Wu PC, Yeoh EK, Yeung CY. Placebo-controlled trial of recombinant alpha 2-interferon in Chinese HBsAg-carrier children. Lancet 1987; 2: 87780 .

13 Lai CL, Lin HJ, Lau JN et al. Effect of recombinant alpha 2 interferon with or without prednisone in Chinese HBsAg carrier children. Q. F. Med. 1991; 78: 155-63.

14 Lok AS, Lai CL, Wu PC, Leung EK. Long-term followup in a randomised controlled trial of recombinant alpha 2-interferon in Chinese patients with chronic hepatitis B infection. Lancet 1988; 2: 298-302.

15 Lok AS, Wu PC, Lai CL et al. A controlled trial of interferon with or without prednisone priming for chronic hepatitis B. Gastroenterology 1992; 102: 2091-7.

16 Liaw YF, Lin SM, Chen TJ, Chien RN, Sheen IS, Chu $\mathrm{CM}$. Beneficial effect of prednisolone withdrawal followed by human lymphoblastoid interferon on the treatment of chronic type B hepatitis in Asians: a randomized controlled trial. F. Hepatol. 1994; 20: 175-80.

17 Cooksley WG, Piratvisuth T, Lee SD et al. Peginterferon alpha-2a $(40 \mathrm{kDa})$ : an advance in the treatment of hepatitis B e antigen-positive chronic hepatitis B. F. Viral Hepat. 2003; 10: 298-305.

18 Dienstag JL, Schiff ER, Wright TL et al. Lamivudine as initial treatment for chronic hepatitis B in the United States. N. Engl. F. Med. 1999; 341: 1256-63.

19 Lai CL, Chien RN, Leung NW et al. A one-year trial of lamivudine for chronic hepatitis B. Asia Hepatitis Lamivudine Study Group. N. Engl. F. Med. 1998; 339: 61-8.

20 Schalm SW, Heathcote J, Cianciara J et al. Lamivudine and alpha interferon combination treatment of patients with chronic hepatitis B infection: a randomised trial. Gut 2000; 46: 562-8.

21 Jonas MM, Kelley DA, Mizerski J et al. Clinical trial of lamivudine in children with chronic hepatitis B. N. Engl. f. Med. 2002; 346: 1706-13.

22 Perrillo RP, Lai CL, Liaw YF et al. Predictors of HBeAg loss after lamivudine treatment for chronic hepatitis $B$. Hepatology 2002; 36: 186-94.

23 Liaw YF. Results of lamivudine trials in Asia. F. Hepatol. 2003; 39 (Suppl. 1): S111-15.

24 Marcellin P, Chang TT, Lim SG et al. Adefovir dipivoxil for the treatment of hepatitis $\mathrm{B}$ e antigen-positive chronic hepatitis B. N. Engl. F. Med. 2003; 348: 808-16.

25 Lim SG, Marcellin P, Tassopoulos NC et al. Lack of ethnic differences in response to adefovir dipivoxil therapy in $\mathrm{HBeAg}+$ and HBeAg- patients with chronic hepatitis B. Hepatology 2003; 34: 714A-715A. 